\title{
Kinetic-free safe optimization of a semibatch runaway reaction:
}

\author{
the nitration of 4-chloro benzotrifluoride.
}

\author{
Francesco Maestri, Renato Rota \\ Politecnico di Milano \\ Dip. di Chimica, Materiali e Ingegneria Chimica "G. Natta" \\ Piazza Leonardo da Vinci, 32 - 20133 Milano - Italy \\ *renato.rota@polimi.it, fax: +390223993180
}

\begin{abstract}
$\underline{\text { Abstract }}$
In this work the general $\Psi$ number criterion for the safe operation of semibatch runaway reactions has been applied to the optimization of a nitration process of primary importance in the agrochemical industry, that is the nitration through mixed acids of 4-chloro benzotrifluoride to produce a widely employed class of fluorinated herbicides.

Such a reaction, as almost all the organic nitrations, belongs to the most critical class of exothermic reaction processes, for which the maximum temperature of the synthesis reaction under adiabatic conditions overcomes the decomposition temperature of the system, without any tempering effect due to a solvent evaporation.

It has been verified that higher productivity operating conditions can be easily implemented through the general $\Psi$ number criterion, even without a kinetic characterization of the system, but just elaborating information already available at the laboratory scale, where the chemical recipe is developed.

The results obtained have been further validated through the boundary and temperature diagrams criterion, which however requires a previous estimation of the reaction kinetic parameters, with a much higher experimental effort.
\end{abstract}

Keywords:

Kinetics; Safety; Semibatch reactor (SBR); 4-chloro benzotrifluoride; $\Psi$ number; Optimization;

Scale-up; Early warning; Boundary diagrams; Temperature diagrams. 


\section{Introduction}

A number of potential runaway reactions of the fine chemical and pharmaceutical industry are better performed dosing one of the reactants (referred to as the coreactant) into the reaction mass at a sufficiently low rate, in order to uniformly spread the reaction heat over a sufficiently wide time interval, according to the heat transfer characteristics of the reactor ${ }^{1-7}$.

Under such conditions, the observed conversion rate is independent on the reaction macrokinetics and is fully controlled by the coreactant supply ${ }^{8}$. Moreover, the reaction temperature peaks occurring as the reaction triggers are effectively limited ${ }^{8,9}$.

Such operating conditions - referred to in the process safety literature as target conditions correspond to a pseudo-steady state regime of the reactor with respect to both the coreactant accumulation and the reaction temperature ${ }^{10}$.

When the dosing time is determined through comparison with the reaction characteristic time (with respect to which it must be significantly higher), the kinetic parameters of the reaction must be previously estimated, since the reaction characteristic time depends on them ${ }^{10}$.

On this basis, a number of safety criteria have been developed in the last 30 years, through which safe and productive operating conditions of an exothermic semibatch reactor (in the following referred to as SBR) can be determined, without solving the mathematical model of the reactor ${ }^{1-7,9,11-}$ 19. However, since they are based on the aforementioned comparison between coreactant dosing time and reaction characteristic time, a previous kinetic characterization of the system is required, which is often difficult to perform when dealing with multipurpose processes of the fine chemical and pharmaceutical industry ${ }^{10}$.

Recently Maestri and Rota $^{10}$ developed a new safety criterion based on an easy to measure process variable referred to as the $\Psi$ number, through which the target SBR regime can be experimentally identified and monitored during the reactor operation. Moreover, the involved measurements can be performed just elaborating fully available process variables and without knowing the reaction kinetic parameters, which have no influence on the SBR target regime: the only information 
required about the system is the reaction heat, as well as the physical characteristics of the substances and mixtures involved, which however are fully available also for the chemist involved in the laboratory scale process development.

In this work the general $\Psi$ number criterion is applied to the optimization of the industrial operating conditions of an aromatic nitration reaction belonging to the most critical category of Stoessel's classification ${ }^{20}$ of exothermic reaction processes, that is the nitration of 4-chloro benzotrifluoride (in the following referred to as 4-chloro BTF) through mixed acids to produce 4-chloro, 3-nitro benzotrifluoride, a chemical intermediate for the synthesis of a widely employed class of fluorinated herbicides. Since the reaction mass undergoes a strongly exothermic and pressure generating decomposition event above a threshold temperature ${ }^{21}$, the reaction can be performed at the industrial scale $100^{\circ} \mathrm{C}$ below the decomposition temperature, according to the so-called $100^{\circ} \mathrm{C}$ rule $^{22}$. This criterion was initially developed in order to provide a simple method to select a safe operating temperature of an exothermic reaction process, when only preliminary DSC data are available ${ }^{22}$.

However, a number of cases of industrial relevance are described in the process safety literature, demonstrating how such a criterion can lead to selecting dangerous operating conditions of SBRs in which potential runaway reactions are performed: at a too low initial reaction temperature corresponds in fact a lower reactivity of the system and hence a higher tendency to accumulate excessive amounts of the dosed species before the reaction triggers, with further uncontrolled reaction temperature peaks ${ }^{8}$. Such phenomena can be counteracted increasing the coreactant dosing time, which however lowers the process productivity.

It is shown that through the general $\Psi$ number criterion ${ }^{10}$ the former operating conditions of the reaction can be easily optimized at the laboratory scale and safely scaled up to the industrial plant, without a previous kinetic characterization of the system, but just arranging information already provided by the chemical recipe. 
The results obtained have been finally validated through a comparison with the results obtained using the boundary and temperature diagrams criterion.

The current paper is therefore focused on the detailed application of the $\Psi$ criterion in the interest of end users, through the kinetic free scale-up of a potentially dangerous nitration reaction of the agrochemical industry.

\section{2. $\underline{\text { Reaction system }}$}

Aromatic nitrations are strongly exothermic reactions (with a heat of reaction ranging from 110 to $150 \mathrm{~kJ} / \mathrm{mol})^{23}$ occurring in heterogeneous (liquid-liquid) systems that, above a threshold temperature, can undergo sudden decomposition events of the gassy type $\mathrm{e}^{24}$, leading to potentially dangerous reactor overpressures.

In order to prevent the loss of control of the reaction and the further triggering of the thermal runaway, multipurpose reactions of this type must be performed in indirectly cooled SBRs in which the organic species to be nitrated is dosed into an anhydrous mixture of sulfuric and nitric acid (typically at the $10 \% \mathrm{w} / \mathrm{w}$ of nitric acid, to which a maximum nitronium ion concentration, $\mathrm{NO}_{2}{ }^{+}$, corresponds) and at a proper temperature, according to the chemical recipe ${ }^{25,26}$.

Since the system involves two liquid phases (one of which, the acid phase, with a relatively high density), reaction vessels with intensive stirring must be employed at the industrial scale, in order to minimize the mass transfer resistances and to increase the heat transfer efficiency.

Moreover, dealing with highly exothermic reactions, a relatively high heat transfer surface must be provided by the reactor (even at the lower filling degrees), through a combination of internal coils and external jacket. Finally, because of the huge amount of heat released when the reaction mass (mainly consisting of concentrated sulfuric acid) is diluted with water, an inert cooling fluid e.g. of the paraffinic type should be employed instead of water, in order to prevent dangerous incidental scenarios arising from a cooling fluid leakage into the reactor, which would cause an overheating of the reaction mass and a further triggering of the thermal runaway ${ }^{27}$. 
In the current case, pure 4-chloro BTF is dosed into an anhydrous mixture of sulfuric and nitric acid at the $9 \% \mathrm{w} / \mathrm{w}$ of nitric acid ${ }^{21}$. The reaction:<smiles>O=[N+]([O-])c1cc([18F])ccc1Cl</smiles>

occurring in the continuous acid phase, has been previously investigated in the literature ${ }^{21}$, obtaining the following rate expression:

$r=3.228 \times 10^{12} \exp \left(-\frac{87260[\mathrm{~kJ} / \mathrm{kmol}]}{R T}\right) m_{A} C_{A, d} C_{B, c}$

where $C_{A, d}$ and $C_{B, c}$ are the concentrations of 4-chloro BTF in the dispersed phase and of nitric acid in the continuous phase respectively and $\mathrm{m}_{\mathrm{A}}=10^{-2}$ is the distribution coefficient of 4-chloro BTF (that is the ratio of its concentrations in the continuous and in the dispersed phase).

Since, as discussed elsewhere ${ }^{21}$, this rate expression together with a suitable mathematical model of the semi-batch reactor ${ }^{7}$ is able to reproduce correctly the experimental behavior, it has been used in the following to reproduce the reactor behavior both at a laboratory scale as well as at a real-size plant scale. Since the aim of this work was to assess the capability of the $\Psi$ number criterion ${ }^{10}$ to scale-up safe and productive operating conditions from the lab-scale to the real-size plant scale for a practical reacting system, the use of simulated data instead of real experimental data is not a severe limitation.

The recipe used at the laboratory scale is summarized in Table 1 . As can be calculated, a 6\% nitric acid excess has been adopted, in order to reach a quantitative conversion of the species to be nitrated during the final reaction completion ${ }^{21}$. The indicated quantity of 4-chloro BTF is dropped into the mixed acids under intensive stirring, through a double blade impeller. Moreover, the reaction temperature must be limited within $80^{\circ} \mathrm{C}$, since above this temperature an undesired second nitration of the reaction product could partially take place ${ }^{21}$. If the reaction temperature does not exceed this threshold value, the over nitration of the product (that is, of 4-chloro 3-nitro BTF) by nitric acid is kinetically negligible even with a large excess of mixed acids, as occurs during the 
supply period: this because the reaction product has two electron drawing substituents of the aromatic ring (that is, the trifluoromethyl and the nitro groups), which strongly deactivate further electrophylic substitutions. Adiabatic calorimetry experiments performed on the reaction mixture in an ARC equipment with a $0.02^{\circ} \mathrm{C} / \mathrm{min}$ accuracy showed that a strongly exothermic and pressure generating decomposition event occurs at $140^{\circ} \mathrm{C}{ }^{21}$. For this reason the reaction was performed at the industrial scale at an initial temperature of $37^{\circ} \mathrm{C}{ }^{21}$, that is nearly $100^{\circ} \mathrm{C}$ below the aforementioned decomposition temperature, according to the so-called $100^{\circ} \mathrm{C}$ rule 22

In the case study here investigated, the 4-chloro BTF is dropped into the mixed acids at a temperature of $60^{\circ} \mathrm{C}$, which is higher than that previously investigated ${ }^{21}$ even if still lower than $80^{\circ} \mathrm{C}$, which is the threshold temperature for the di-nitration reaction identified by an ARC test ${ }^{21}$. In this way, the reaction heat is also removed at higher temperatures, at which, as a relevant difference with respect to the operating conditions previously considered, no refrigeration cycles must be used at the industrial scale to keep the system cooled, such as those needed to perform the reaction $20^{\circ} \mathrm{C}$ below (that is, at $37^{\circ} \mathrm{C}$ vs. 60) and with a cooling fluid average temperature reasonably not higher than $5 \div 10^{\circ} \mathrm{C}$.

The adiabatic temperature rise of the reaction:

$\Delta T_{a d}=\frac{\left(-\Delta \widetilde{H}_{r}\right) \times n_{A, d o s}}{\left(m \hat{C}_{P}\right)_{c}+\left(m \hat{C}_{P}\right)_{d}}$

is equal to $99.3^{\circ} \mathrm{C}$, where $\mathrm{n}_{\mathrm{A}, \mathrm{dos}}$ is the molar amount of dosed 4-chloro $\mathrm{BTF}$, equal to $181.3 \mathrm{~g} / 180.5 \mathrm{~g} / \mathrm{mol}=1.0044 \mathrm{~mol}$, the initial mass of the continuous phase (that is, of mixed acids), $\mathrm{m}_{\mathrm{c}}$, is equal to $688.05 \mathrm{~g}$ with a heat capacity of $1.477 \mathrm{~J} /\left(\mathrm{g}^{\circ} \mathrm{C}\right){ }^{28}$, the mass of dosed dispersed phase (that is, of 4-chloro BTF), $\mathrm{m}_{\mathrm{d}}$, is equal to $181.3 \mathrm{~g}$ with a heat capacity of $1.257 \mathrm{~J} /\left(\mathrm{g}^{\circ} \mathrm{C}\right){ }^{28}$, and the reaction heat is equal to $-123 \mathrm{~kJ} / \mathrm{mol}$.

Under the conditions above the maximum temperature of the synthesis reaction, MTSR, is $60+99.3 \cong 160^{\circ} \mathrm{C}$, which is above the decomposition temperature of the reaction mass (that is, 
$\left.140^{\circ} \mathrm{C}\right)$. Therefore the reaction belongs to the most critical category of Stoessel's classification of exothermic reaction processes ${ }^{20}$.

\section{Process optimization and scale-up}

On the basis of the laboratory recipe described above, the operating conditions of the full scale reactor in terms of coreactant dosing time must be safely identified, through their safety investigation at a lower scale and the further scale-up to the industrial plant ${ }^{7,10}$. In the current case, $\mathrm{RC} 1$ isoperibolic tests have been considered at the lower scale in a $1.2 \mathrm{~L}$ equipment, in which a suitable dosing time of the coreactant has been easily identified through the general $\Psi$ number criterion. The dosing time for the RC1 reactor has been then scaled-up to the industrial SBR. It must be noticed that at the lower scale, any reaction equipment can be employed, provided that the heat exchange rates between the reaction system and the cooling fluid can be measured.

In this way, even without any information about the reaction kinetics, the percentage ratio between the actual and the target heat removal rates (by both the external coolant and the dosing stream) can be measured, the latter being proportional to the product of the reaction enthalpy and the coreactant flow rate: if the SBR is operated under a low accumulation - high heat transfer efficiency operating regime such a ratio, referred to as the $\Psi$ number ${ }^{10}$, quickly reaches values close to 100 , and the corresponding operating conditions can be accepted.

For the current case study, an industrial $9 \mathrm{~m}^{3}$ SBR equipped with a two blade impeller providing an intensive and uniform stirring of the reaction mass has been considered. Moreover, a combination of internal coils and jacket provides a $45 \mathrm{~m}^{2}$ heat transfer surface at the lowest reactor filling degrees: in Table 2 the geometry and operating conditions of the RC1 and of the industrial SBR are summarized, as well as their heat transfer characteristics that can be easily determined in practice through proper calibration tests.

About the industrial SBR heat transfer efficiency, it can be noticed that for a high turbulence reaction vessel such as those employed for generating stable liquid-liquid emulsions between an 
organic and an aqueous acidic phase ${ }^{29}$, Westerterp and Molga ${ }^{30}$ provide typical values of the Westerterp number ${ }^{31}$ :

$W t=\frac{(U A)_{0} t_{d o s}}{\varepsilon\left(\widetilde{\rho} \tilde{C}_{P} V_{r}\right)_{0}}$

as a function of the reactor volume, for both the cases of a continuous organic phase and of a continuous aqueous phase. In the latter case (corresponding to the reaction system in question) and for a $9 \mathrm{~m}^{3}$ reactor equipped with both an internal coil and an external jacket, the Westerterp number for a one hour coreactant dosing time is close to 10 . Such a value corresponds for the reaction system in question to an overall heat transfer coefficient ranging from 250 to $300 \mathrm{~W} /\left(\mathrm{m}^{2} \mathrm{~K}\right)$, which is in agreement with the reference technical literature ${ }^{29}$.

The coreactant dosing time must be selected at the lower scale taking into account that:

- the accumulation phenomena in the system must be effectively minimized, so that a feed interruption at any time results in a sudden SBR shut down, hence keeping the process safe;

- the reaction temperature increase with respect to its initial value must be limited within $20^{\circ} \mathrm{C}$ (that is, the reaction temperature must range between 60 and $80^{\circ} \mathrm{C}$ ), since, as stated by the chemical recipe, above $80^{\circ} \mathrm{C}$ the undesired di-nitration of the product could be triggered.

On the basis of the laboratory recipe summarized in Table 1, before simulating the RC1 experiments aimed to identify the proper dosing time through the $\Psi$ number criterion, a reasonable estimation of the dosing time can be obtained assuming:

- $\quad$ an average temperature, $\bar{T}$, during the supply period, according to the allowable reaction temperature rise with respect to its initial value. Moreover, it must be considered that such an excursion is in almost all the cases relatively limited, since the chemical recipe typically states that the reaction temperature during the coreactant supply ranges within a narrow interval around a selected value. According to such a constraint, even theoretical isothermal conditions during the supply period stated by the chemical recipe, are well approximated at the industrial scale operating the SBR under isoperibolic conditions with a relative narrow 
temperature rise above the initial value ${ }^{8}$. Such conditions can be achieved adopting a sufficiently wide coreactant dosing time, according to the reaction enthalpy and to the heat transfer characteristics of the employed reaction vessel;

- an average heat transfer efficiency during the supply period between its initial and end dosing values (that is, taking into account for the heat transfer surface increase as the reactor is filled).

With the aforementioned assumptions and at high $\Psi$ number values (such as those characterizing well ignited semibatch reactions operated within a relatively narrow temperature range) the following expression for the dosing time estimation can be derived along the lines discussed in ${ }^{10}$ :

$t_{d o s} \cong m_{d o s} \frac{\frac{{ }^{\omega} A, d o s}{v_{A}}\left(-\Delta \widehat{H}_{r}\right)+\hat{C}_{P, d o s}\left(T_{\text {dos }}-\bar{T}\right)}{(U A)_{\text {avg }}\left(\bar{T}-T_{\text {cool }}\right)}$

stating that the reaction enthalpy contribution is instantaneously balanced during the coreactant supply by the enthalpy change of the external coolant and of the dosing stream, at the assumed reaction temperature and under an average heat transfer efficiency for the SBR between the initial and the end dosing conditions. In the equation above the $\Delta \widehat{H}_{r}$ term is the reaction enthalpy referred to the mass of reacted coreactant, that is equal to $-123000 \mathrm{~J} / \mathrm{mol} / 180.5 \mathrm{~g} / \mathrm{mol}=-681.4 \mathrm{~J} / \mathrm{g}$. It must be noticed that in deriving equation (5) the assumption of a well ignited quick onset reaction system is in most cases coherent with the chemical recipe for performing an exothermic semibatch reaction, according to which the coreactant supply is normally started under high reactivity operating conditions, even at the laboratory scale.

In this way the information contained in the chemical recipe are easily translated by the process engineer in a time period in which, at any scale, the reaction heat evolution must be spread, in order to keep the temperature excursion within a selected range.

It must be stressed that the only information needed about the reaction system are the reaction enthalpy and the physical characteristics (in terms of density and heat capacity) of the products and mixtures involved. No kinetic characterization of the system is required, which is often difficult to 
achieve when dealing with multipurpose processes of the fine chemical and pharmaceutical industry, taking into account also for the simultaneous occurrence of mass transfer phenomena in heterogeneous systems. Such a possibility arises from the fact that through the $\Psi$ number the displacement of the SBR operating conditions from the target ones can be directly measured through easily available process variables, that is the reaction temperature, the coolant flow rate and temperature increase across the jacket and coil and the dosing stream flow rate and temperature ${ }^{10}$.

For the reaction here considered, a coreactant dosing time at the RC1 scale equal to 3277s (that is, $\approx 55^{\prime}$ ) can be estimated through equation (5), that must be now experimentally validated through isoperibolic reaction runs at the same scale, in which the $\Psi$ number ${ }^{10}$ :

$$
\Psi=\frac{F_{\text {dos }} \tilde{C}_{P, \text { dos }}\left(T-T_{\text {dos }}\right)+\dot{m}_{\text {cool }} \hat{C}_{P, \text { cool }}\left(T_{\text {cool }, \text { oUT }}-T_{\text {cool }, I N}\right)}{\frac{F_{A, d o s}}{v_{A}}\left(-\Delta \widetilde{H}_{r}\right)} \times 100
$$

is measured and compared at a suitable fraction of the dosing time with an expected lower limit. About the target $\Psi$ number value, it must be taken into account that when the reaction quickly triggers under high cooling efficiency conditions, the $\Psi$ number quickly reaches in any case values ranging from 80 to $100{ }^{10}$ : therefore a minimum $\Psi$ number equal to 80 can be assumed.

About the time at which to perform the aforementioned check, a relatively early fraction of the dosing time should be selected, in order to limit the potential accumulation phenomena in the SBR, even dealing with a not ignited reaction system ${ }^{10}$.

Moreover, it must be taken into account that when selecting the SBR operating conditions, the $\Psi$ number values in the first fraction of the supply period show a relatively high dependence on the dosing time: according to the mentioned literature ${ }^{10}$, the check on the $\Psi$ number value could be set at the $20 \%$ of the supply period, provided that the maximum temperature of the synthesis reaction due to the sudden consumption under adiabatic conditions of the whole coreactant dosed amount is far below the maximum allowable temperature. When the $20 \%$ of the coreactant has been supplied 
to the reactor, the corresponding sudden release of the reaction heat would lead to an adiabatic temperature rise:

$\Delta T_{a d, 20 \%}=\frac{\left(-\Delta \widetilde{H}_{r}\right) \times 0.2 n_{A, d o s}}{\left(m \hat{C}_{P}\right)_{c}+0.2\left(m \hat{C}_{P}\right)_{d}}$

equal to $23.3^{\circ} \mathrm{C}$, to which a MTSR equal to $60+23.3=83.3^{\circ} \mathrm{C}$ corresponds (which is far below the system decomposition temperature, equal to $140^{\circ} \mathrm{C}$ ).

On the basis of the model equations reported in the Supporting Information section (see paragraph S1 for mass balances and paragraph S2 for the SBR energy balance), performing the simulations of the RC1 runs with the coreactant dosing time estimated above, the time profiles of the $\Psi$ number and of the reaction temperature plotted in Figures 1 and 2 have been obtained. It can be noticed that once the $20 \%$ of the coreactant amount has been supplied, the $\Psi$ number reaches values higher than 80, from which it can be concluded that the selected dosing time allows to fulfill at the RC1 scale the process constraints and safety requirements stated by the chemical recipe: otherwise, a higher dosing time is required. It is worth noting that the dosing time estimation given by equation (5) allows for minimizing the number of laboratory-scale experiments required to identify the proper operating conditions, providing in most cases a satisfactory approximation of the dosing time itself, according to the selected average reaction temperature and to the reaction vessel heat transfer efficiency. In this way and taking into account that no kinetic characterization of the system is required, a significant amount of time can be saved for the laboratory scale experiments.

With the dosing time identified above and according to the geometric and heat transfer characteristics of the RC1 reactor, a Westerterp number (4) at the laboratory scale equal to 30 can be calculated.

Once the laboratory scale operating conditions have been chosen, their scale-up to the industrial reactor must be performed. According to the safety criterion reported in the process safety literature ${ }^{7}$, such a scale-up can be safely performed keeping the Westerterp number constant, that is increasing the coreactant dosing time by the same factor corresponding to the decrease of the heat 
transfer efficiency per unit volume, $\mathrm{UA} / \mathrm{V}$, when moving from the lower to the full scale reaction vessel.

In this way, the reactivity number ${ }^{13}$ :

$R_{y}=\frac{v_{A} D a R E \kappa_{0}}{\varepsilon\left(W t+R_{H}\right)}$

increases as well for the full scale plant, since the Westerterp number is kept constant whereas the Damköhler number increases by a factor given by the ratio of the full to the laboratory scale dosing times:

$D a_{I N D}=D a_{L A B} \frac{t_{d o s, I N D}}{t_{d o s, L A B}}$

The scale-up process is therefore safe, leading to a reactivity number (8) at the industrial scale higher than that at the laboratory scale.

From the calculated Westerterp number (which is equal at both the scales, as specified above) and through the geometric and heat transfer characteristics of the industrial reactor summarized in Table 2, a coreactant dosing time at the industrial scale close to 3 hours can be finally estimated.

On the basis of the model equations reported in the Supporting Information section (see paragraph S1 for mass balances and paragraph S2 for the SBR energy balance), in Figures 3 and 4 the simulated time profiles of the $\Psi$ number and of the reaction temperature for the industrial SBR have been plotted.

In Table 3 a stepwise chart for the application of the $\Psi$ criterion is finally reported, summarizing the process and plant information required at each step of the described procedure.

The presented criterion allows therefore for a simple (that is, based on simple measurements of available process variables), general (that is, not requiring a macrokinetic characterization of the system) and safe selection and scale-up of the operating conditions of potential runaway reactions performed in indirectly cooled SBRs.

Moreover, as a key improvement with respect to the available safety criteria for the selection of safe operating conditions of exothermic SBRs, the $\Psi$ number criterion allows for easily monitoring the 
SBR safe operation during each industrial batch of a productive campaign ${ }^{10}$. As represented in Figure 5, through a simple elaboration of process signals already available on every industrial SBR, the $\Psi$ number time profile during the supply period can be easily calculated and a process check on the $\Psi$ numbers reached in the first fraction of the supply period (with respect to a suitable lower limit) can therefore be easily performed. In this way the SBR can be always operated at low accumulation and high cooling efficiency conditions and unexpected reaction inhibitions or heat transfer efficiency drops can be early detected. The process safety can in this cases be preserved through a prompt interruption of the coreactant feed, allowing at any time to shut down the SBR with a minimum delay, as a consequence of the low unreacted coreactant accumulation. Therefore, for what concerns the industrial adoption of the criterion, the measurement of $\Psi$ on the SBR is not necessarily part of a control loop acting on a final process variable (such as, the feed rate) according to a given control logic. $\Psi$ is simply a measured variable and an alert is triggered when its value in the first fraction of the supply period is far below the band ranging from 80 to 100 . Moreover, according to the control logic represented in Figure 5 just for the sake of example, a switch-low interruption of the coreactant feed can be coupled with the aforementioned alert. This logic is very simple (and therefore robust) and no complexities in its use have been observed at the industrial scale $^{10}$.

\section{Validation of the results through the boundary and temperature diagrams criterion}

The operating conditions previously selected for the SBR through the general $\Psi$ number criterion have been validated through the combined boundary and temperature diagrams method, according to the procedure presented elsewhere in the literature ${ }^{7}$. However, as a relevant difference with the $\Psi$ number approach, the boundary and temperature diagrams method requires a previous characterization of the reaction kinetics.

Under target conditions for the SBR, the reactor temperature time behavior is determined by the reaction exothermic contribution, occurring at the time scale of the coreactant dosing. Therefore, the 
temperature diagrams tend to overlap into a single temperature rise curve ${ }^{7}$, which can be safely used for any reaction type and in a wide range of the involved dimensionless parameters (see Figure 6). Since for the reaction system in question the temperature must range between 60 and $80^{\circ} \mathrm{C}$, the corresponding dimensionless temperature increase:

$\phi=\left.\frac{T_{\max }}{T_{0}}\right|_{\max }$

is equal to $353.15 \mathrm{~K} / 333.15 \mathrm{~K}=1.06$.

Entering the general temperature rise curve of Figure 6 with this $\phi$ value, an exothermicity number:

$E_{x}=\frac{\gamma}{\breve{T}_{0}^{2}} \frac{\Delta \breve{T}_{a d, 0}}{\varepsilon\left(W t+R_{H}\right)}$

ranging from 1 to 1.5 can be read off.

With the values of the involved dimensionless parameters for the industrial SBR (summarized in Table 4), a Westerterp number of the order of $25 \div 30$ can be easily calculated, from which, with the SBR characteristics reported in Table 2, a coreactant dosing time of around $2 \mathrm{~h} 45^{\prime}$ can be estimated as well: such a result is in agreement with that obtained through the general $\Psi$ number criterion.

With the calculated dosing time and on the basis of the reaction rate expression (2), a $v_{A} \operatorname{DaRE}$ parameter equal to 0.567 and a reactivity number, $\mathrm{R}_{\mathrm{y}}$, equal to 1.87 can be calculated for the industrial SBR, which is much higher than the corresponding QFS lower limit for $(1,1)$ slow reactions occurring in the continuous phase, which is equal to $0.015^{30}$.

Therefore, the assumption of QFS operating conditions holds true, and the results obtained can be accepted.

\section{5. $\underline{\text { Conclusions }}$}

The $\Psi$ number and the boundary and temperature diagrams criteria allow for identifying safe and productive operating conditions for indirectly cooled SBRs in which potential runaway reactions are performed, without solving the mathematical model of the reactor. 
However the $\Psi$ number criterion allows for selecting the aforementioned operating conditions without a previous kinetic characterization of the system, since it is based on a direct and general measure of the displacement between actual and target operating regime of the SBR, performed through available process variables.

Moreover, monitoring the $\Psi$ number during each production batch, it is possible to early detect dangerous incidental scenarios, arising from unexpected reactivity and/or heat transfer efficiency drops.

Through the $\Psi$ number criterion the industrial operating conditions of a potential runaway nitration reaction of the agrochemical industry have been successfully revised, enhancing the process safety and productivity.

\section{Nomenclature}

$\begin{array}{ll}\mathrm{A} & \text { heat transfer surface, } \mathrm{m}^{2} \\ \mathrm{C} & {\text { molar concentration, } \mathrm{kmol} / \mathrm{m}^{3}} \\ \mathrm{Da} & =\mathrm{k}_{\mathrm{R}} \mathrm{t}_{\text {dos }} \mathrm{C}_{\mathrm{B} 0}, \text { Damköhler number, - } \\ \mathrm{E} & \text { activation energy, } \mathrm{kJ} / \mathrm{kmol} \\ \mathrm{E}_{\mathrm{x}} & =\frac{\gamma}{\breve{T}_{0}^{2}} \frac{\Delta \breve{T}_{a d, 0}}{\varepsilon\left(W t+R_{H}\right)}, \text { exothermicity number, - } \\ \tilde{C}_{P} & \text { molar heat capacity at constant pressure, } \mathrm{kJ} /(\mathrm{kmol} \cdot \mathrm{K}) \\ \hat{C}_{P} & \text { mass heat capacity at constant pressure, } \mathrm{kJ} /(\mathrm{kg} \cdot \mathrm{K}) \\ \mathrm{F} & \text { molar flow rate, } \mathrm{kmol} / \mathrm{s} \\ \mathrm{k} & \text { reaction rate constant, } \mathrm{m}^{3} /(\mathrm{kmol} \cdot \mathrm{s}) \\ \mathrm{m} & \text { mass, kg } \\ \mathrm{m} & \text { distribution coefficient, - } \\ \mathrm{MTSR} & \text { maximum temperature of the synthesis reaction, } \mathrm{K} \\ \dot{m} & \text { mass flow rate, } \mathrm{kg} / \mathrm{s} \\ \mathrm{n} & \text { number of moles, } \mathrm{kmol} \\ \mathrm{N} & \text { stirring speed, rpm } \\ \mathrm{r} & \text { reaction rate, } \mathrm{kmol} /\left(\mathrm{m}^{3} \cdot \mathrm{s}\right) \\ \mathrm{R} & \text { ideal gas constant }=8.314 \mathrm{~kJ} /(\mathrm{kmol} \cdot \mathrm{K}) \\ \mathrm{RE} & =\mathrm{m}_{\mathrm{A}}, \text { reactivity enhancement factor, - } \\ \mathrm{R}_{\mathrm{H}} & =\left(\rho C_{P}\right)_{d} /\left(\rho C_{P}\right)_{c}, \text { heat capacity ratio, - } \\ \mathrm{R}_{\mathrm{y}} & =\frac{v_{A} D a R E \kappa_{0}}{\varepsilon\left(W t+R_{H}\right)}, \text { reactivity number, - } \\ \mathrm{t} & \text { time, } \mathrm{s} \\ \mathrm{T} & \text { temperature, } \mathrm{K} \\ \bar{T} & \text { average temperature, } \mathrm{K} \\ \breve{T} & =\mathrm{T} / \mathrm{T}_{\mathrm{R}}, \text { dimensionless temperature, - } \\ & \end{array}$


$\mathrm{U} \quad$ overall heat transfer coefficient, $\mathrm{kW} /\left(\mathrm{m}^{2} \mathrm{~K}\right)$

$\mathrm{V}$ reaction volume, $\mathrm{m}^{3}$

Wt $\quad=\frac{(U A)_{0} t_{d o s}}{\varepsilon\left(\widetilde{\rho} \tilde{C}_{P} V_{r}\right)_{0}}$, Westerterp number, -

Subscripts and superscripts

act activation

ad adiabatic

avg average

$\mathrm{A}$ and $\mathrm{B}$ components $\mathrm{A}$ and $\mathrm{B}$

cool coolant

c continuous phase

d dispersed phase

dec decomposition

dos dosing stream or dosing time

IN inlet

IND industrial

LAB laboratory

max maximum

OUT outlet

QFS quick onset, fair conversion, smooth temperature profile

$\mathrm{r}$ reaction

$\mathrm{R} \quad$ reference

0 start of the semibatch period

Greek symbols

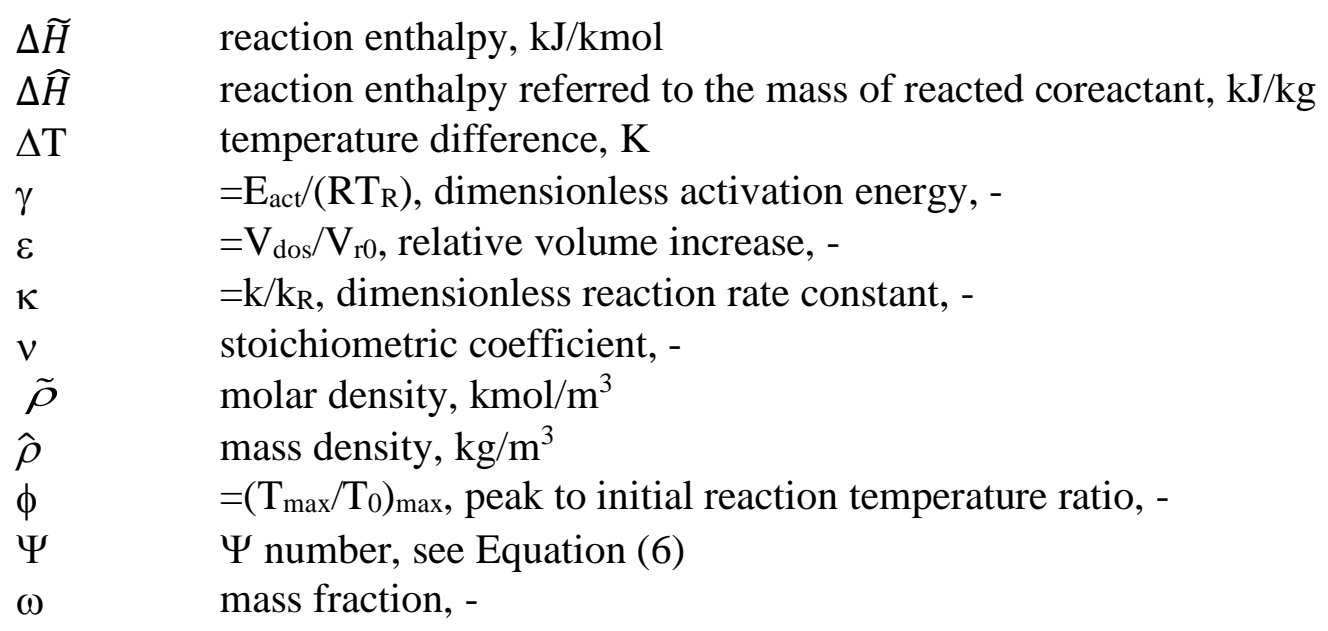




\section{Supporting Information}

S1 Mass balances

S2 Energy balance

This information is available free of charge via the Internet at http://pubs.acs.org. 


\section{$\underline{\text { References }}$}

(1) Steensma, M.; Westerterp, K. R. Thermally Safe Operation of a Cooled Semi-batch Reactor. Slow Liquid-liquid Reactions. Chem. Eng. Sci. 1988, 43, 2125.

(2) Steensma, M.; Westerterp, K. R. Thermally Safe Operation of a Semibatch Reactor for Liquidliquid Reactions. Slow Reactions. Ind. Eng. Chem. Res. 1990, 29, 1259.

(3) Steensma, M.; Westerterp, K. R. Thermally Safe Operation of a Semibatch Reactor for Liquidliquid Reactions. Fast Reactions. Chem. Eng. Technol. 1991, 14, 367.

(4) Maestri, F.; Rota, R. Thermally Safe Operation of Liquid-liquid Semibatch Reactors. Part I: Single Kinetically Controlled Reactions with Arbitrary Reaction Order. Chem. Eng. Sci. 2005, 60, 3309.

(5) Maestri, F.; Rota, R. Thermally Safe Operation of Liquid-liquid Semibatch Reactors. Part II: Single Diffusion Controlled Reactions with Arbitrary Reaction Order. Chem. Eng. Sci. 2005, 60, 5590.

(6) Maestri, F.; Rota, R. Safe and Productive Operation of Homogeneous Semibatch Reactors. I: Development of a General Procedure. Ind. Eng. Chem. Res. 2006, 45, 8002.

(7) Maestri, F.; Copelli, S.; Rota, R.; Lunghi, A.; Gigante, L.; Cardillo, P. Simple Procedure for Optimal Scale-up of Fine Chemical Processes. I: Practical Tools. Ind. Eng. Chem. Res. 2009, 48 (3), 1307.

(8) Steinbach, J. Safety Assessment for Chemical Processes; Wiley-VCH: Weinheim, 1999.

(9) Maestri, F.; Rota, R. Temperature Diagrams for Preventing Decomposition or Side Reactions in Liquid-liquid Semibatch Reactors. Chem. Eng. Sci. 2006, 61, 3068.

(10) Maestri, F.; Rota, R. Kinetic-free Safe Operation of Fine Chemical Runaway Reactions: a General Criterion. Ind. Eng. Chem. Res. 2016, 55, 925.

(11) Hugo, P.; Steinbach, J. Praxisorientierte Darstellung der Thermischen Scherheitsgrenzen für den Indirekt Gekühlten Semibatch Reaktor. Chem. Ing. Tech. 1985, 57, 780. 
(12) Hugo, P.; Steinbach, J. A Comparison of the Limits of Safe Operation of a SBR and a CSTR. Chem. Eng. Sci. 1986, 41, 1081.

(13) Stoessel, F. Thermal Safety of Chemical Processes, Risk Assessment and Process Design; Wiley-VCH: Weinheim, 2008.

(14) Molga, E. J.; Lewak, M; Westerterp, K. R. Runaway Prevention in Liquid-phase Homogeneous Semibatch Reactors. Chem. Eng. Sci. 2007, 62, 5074.

(15) Copelli, S.; Derudi, M.; Maestri, F.; Rota, R. Safe Operating Conditions for Semibatch Processes Involving Consecutive Reactions with Autocatalytic Behavior. Chem. Eng. Sci. 2010, 65, 5464.

(16) Copelli, S.; Torretta, V.; Pasturenzi, C.; Derudi, M.; Cattaneo, C. S.; Rota, R. On the Divergence Criterion for Runaway Detection: Application to Complex Controlled Systems. Journal of Loss Prevention in the Process Industries 2014, 28, 92.

(17) Copelli, S.; Derudi, M.; Rota, R. Topological Criteria to Safely Optimize Hazardous Chemical Processes Involving Consecutive Reactions. Ind. Eng. Chem. Res. 2010, 49, 4583.

(18) Copelli, S.; Derudi, M.; Lunghi, A.; Pasturenzi, C.; Rota, R. Experimental Design of Topological Curves to Safely Optimize Highly Exothermic Complex Reacting Systems. Ind. Eng. Chem. Res. 2011, 50, 9910.

(19) Copelli, S.; Derudi, M.; Rota, R. Topological Criterion to Safely Optimize Hazardous Chemical Processes Involving Arbitrary Kinetic Schemes. Ind. Eng. Chem. Res. 2011, 50, 1588.

(20) Stoessel, F. What is your Thermal Risk? Chem. Eng. Prog. 1993, 89, 68.

(21) Maestri, F.; Copelli, S.; Rota, R.; Lunghi, A.; Gigante, L.; Cardillo, P. Simple Procedure for Optimal Scale-up of Fine Chemical Processes. II: Nitration of 4-Chlorobenzotrifluoride. Ind. Eng. Chem. Res. 2009, 48 (3), 1316.

(22) Hofelich, T. C.; Thomas R. C. The Use/Misuse of the 100 Degree Rule in the Interpretation of Thermal Hazard Tests. International Symposium On Runaway Reactions, CCPS, Boston, 1989, 74. (23) Cardillo, P. Incidenti in Ambiente Chimico. Guida allo studio e alla valutazione delle reazioni 
fuggitive; Stazione Sperimentale per i Combustibili: San Donato Milanese, 1998.

(24) Etchells, J.D.; Wilday, J. Workbook for Chemical Reactor Relief System Sizing. HSE Contract Research Report Number 136, ISBN 071761389 5, HSE Books, 1998.

(25) Zaldivar, J. M., Molga, E.; Alós, M. A.; Hernández, H.; Westerterp, K. R. Aromatic Nitrations by Mixed Acids. Slow Liquid-liquid Reaction Regime. Chemical Engineering and Processing: Process Intensification 1995, 34, 543.

(26) Zaldivar, J. M., Molga, E.; Alós, M. A.; Hernández, H.; Westerterp, K. R. Aromatic Nitrations by Mixed Acids. Fast Liquid-liquid Reaction Regime. Chemical Engineering and Processing: Process Intensification 1996, 35, 91.

(27) Copelli, S.; Derudi, M.; Cattaneo, C. S.; Nano, G.; Raboni, M.; Torretta, V.; Rota, R. Synthesis of 4-chloro 3-nitro benzotrifluoride: Industrial Thermal Runaway due to Cooling System Failure. Process Safety and Environmental Protection 2014, 92, 659.

(28) Yaws, C. L. Chemical Properties Handbook; McGraw Hill, 1998.

(29) Green, D. W.; Perry, R. H. Chemical Engineers' Handbook; Eighth Edition, McGraw Hill: New York, 2008.

(30) Westerterp, K. R.; Molga, E. J. No More Runaways in Fine Chemical Reactors. Ind. Eng. Chem. Res. 2004, 43, 4585.

(31) Pohorecki, R.; Molga, E. Letter to the Editor: the Westerterp Number (Wt). Chem. Eng. Res. Des. 2010, 88, 385. 


\section{Captions to the figures}

Figure 1. RC1 reactor. Parameter values as in Table 2 and dosing time equal to 55'. $\Psi$ number vs. time.

Figure 2. RC1 reactor. Parameter values as in Table 2 and dosing time equal to 55'. Reactor temperature vs. time.

Figure 3. Industrial SBR. Parameter values as in Table 2 and dosing time equal to 180'. $\Psi$ number vs. time.

Figure 4. Industrial SBR. Parameter values as in Table 2 and dosing time equal to 180'. Reactor temperature vs. time.

Figure 5. SBR control logic for monitoring the reactor operation.

Figure 6. General temperature rise curve for exothermic SBRs operating in the QFS regime. 


\section{$\underline{\text { Tables }}$}

Amount:

$67.05 \mathrm{~g}$

$621 \mathrm{~g}$ $688.05 \mathrm{~g}$ ( $\equiv 382.9 \mathrm{~cm}^{3}$ with $\hat{\rho}_{c}=1787 \mathrm{~kg} / \mathrm{m}^{3}$ )

Dosed coreactant (1):

$$
\text { 181.3g ( } \left.\equiv 134 \mathrm{~cm}^{3} \text { with } \hat{\rho}_{d}=1353 \mathrm{~kg} / \mathrm{m}^{3}\right)
$$

4-chloro BTF

Initial temperature:

$60^{\circ} \mathrm{C}$

Maximum temperature (2): $\quad 80^{\circ} \mathrm{C}$

Decomposition temperature: $\quad 140^{\circ} \mathrm{C}$

Table 1. Chemical recipe at the laboratory scale.

Notes:

1) the coreactant (4-chloro BTF) must be dosed under intensive stirring, that must be kept all along the reaction process;

2) the temperature rise occurring at the SBR onset, must be limited within $20^{\circ} \mathrm{C}$, since at $80^{\circ} \mathrm{C}$ the undesired product di-nitration can be triggered.

22

DOI: 10.1021/acs.iecr.6b03590 


\section{$\underline{\mathrm{RC} 1 \text { reactor }}$}

Volume:

1.2L

$\mathrm{V}_{\mathrm{c}}=382.9 \mathrm{~cm}^{3}$

$\mathrm{V}_{\mathrm{d}}=134 \mathrm{~cm}^{3}$

Initial heat transfer surface: $\quad 2.042 \times 10^{-2} \mathrm{~m}^{2}$

Stirring speed:

500rpm

Initial UA:

$3.15 \mathrm{~W} / \mathrm{K}$

Final UA:

$4.25 \mathrm{~W} / \mathrm{K}$

\section{Industrial SBR}

Volume:

Initial heat transfer surface:

Stirring speed:

Initial UA:

Final UA:
$9 m^{3}$

$45 \mathrm{~m}^{2}$

400rpm

$12 \mathrm{~kW} / \mathrm{K}$

$16.2 \mathrm{~kW} / \mathrm{K}$

$$
\mathrm{V}_{\mathrm{c}}=4.688 \mathrm{~m}^{3}
$$$$
\mathrm{V}_{\mathrm{d}}=1.641 \mathrm{~m}^{3}
$$

Table 2. Geometry and operating conditions of the RC1 reactor and of the industrial SBR. 


\begin{tabular}{|c|c|c|c|c|}
\hline Step & Scale & Operation & Required information & Employed equations \\
\hline \multicolumn{5}{|c|}{ A) SAFE OPERATING CONDITIONS SELECTION AND SCALE-UP } \\
\hline 1) & & 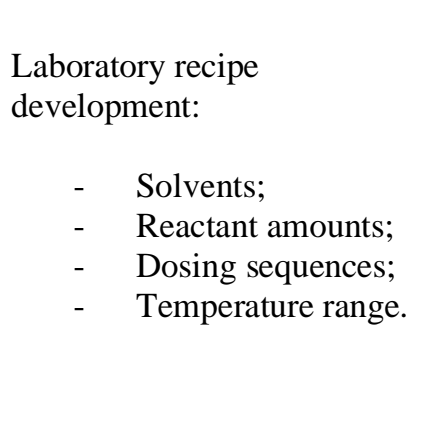 & $\begin{array}{l}\text { Reaction information: } \\
\begin{array}{ll} & \text { Process chemistry (with } \\
\text { constraints e.g. on } \\
\\
\left.\mathrm{T}_{\max }\right) ; \\
\text { - } \\
\text { Process safety ( } \mathrm{T}_{\mathrm{dec}} \\
\text { estimation); } \\
\text { - } \quad \text { Thermodynamic } \\
\\
\text { properties estimation: } \\
\left(\hat{\rho}, \hat{C}_{P}, \Delta \widetilde{H}_{r}\right)\end{array}\end{array}$ & Eq. $3\left(\Delta \mathrm{T}_{\mathrm{ad}}\right.$ calculation $)$ \\
\hline 2) & 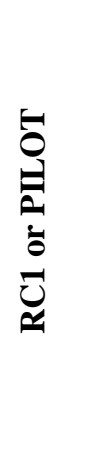 & $\begin{array}{l}\text { Safe operation at the lower } \\
\text { scale ( } \mathrm{t}_{\text {dos }} \text { selection): } \\
\begin{array}{ll}\text { - } & \text { Thermal calibration } \\
& \text { of the reactor; } \\
- & \mathrm{t}_{\text {dos }} \text { estimation; } \\
- & \text { Reaction runs with } \\
& \text { I measurement and } \\
& \mathrm{t}_{\text {dos }} \text { validation; } \\
- & \text { Wt estimation. }\end{array}\end{array}$ & $\begin{array}{ll}\text { - } & \text { Reaction vessel } \\
& \text { geometry; } \\
\text { - } & \text { Heat transfer } \\
& \text { characteristics of the } \\
& \text { reactor (UA); } \\
\text { - } & \text { Coolant characteristics; } \\
\text { - } & \text { Reaction runs data } \\
& \text { (dosing flowrate and } \\
\text { temperature, coolant } \\
\text { flowrate and } \Delta \mathrm{T} \text {, reactor } \\
\text { temperature). }\end{array}$ & $\begin{array}{ll}\text { - } & \text { Eq. } 4(\mathrm{Wt} \\
& \text { calculation); } \\
\text { - } & \text { Eq. } 5\left(\mathrm{t}_{\mathrm{dos}}\right. \\
& \text { estimation); } \\
\text { - } & \text { Eq. } 6(\Psi \\
& \text { calculation). }\end{array}$ \\
\hline 3) & 究 & $\begin{array}{l}\text { Scale-up of the operating } \\
\text { conditions }\left(t_{\text {dos }}\right) \text { to the } \\
\text { industrial SBR: } \\
\text { - Thermal calibration } \\
\text { of the reactor; } \\
\text { - Wt conservation at } \\
\text { the industrial scale. }\end{array}$ & $\begin{array}{ll}\text { - } & \text { Reaction vessel } \\
\text { geometry; }\end{array}$ & Eq. 4 (Wt calculation) \\
\hline \multicolumn{5}{|c|}{ B) SAFE OPERATING CONDITIONS MONITORING } \\
\hline 4) & 疍 & $\begin{array}{l}\text { Monitoring of the SBR } \\
\text { operation during each batch } \\
\text { through the } \Psi \text { trend. }\end{array}$ & $\begin{array}{l}\text { Process data recording (dosing } \\
\text { flowrate and temperature, } \\
\text { coolant flowrate and } \Delta \mathrm{T} \text {, reactor } \\
\text { temperature). }\end{array}$ & Eq. 6 ( $\Psi$ calculation $)$ \\
\hline
\end{tabular}

Table 3. Stepwise procedure for the $\Psi$ criterion application and required information. 


$\begin{array}{ll}\gamma & 35 \\ \Delta \breve{T}_{a d, 0} & 0.43 \\ \varepsilon & 0.35 \\ \mathrm{R}_{\mathrm{H}} & 0.6444\end{array} \quad \Rightarrow$ (with $\left.\mathrm{E}_{\mathrm{x}}=1 \div 1.5\right), \mathrm{Wt}=25 \div 30$

Table 4. Dimensionless parameters for the industrial SBR.

Notes:

1) the parameters in Table 4 have been calculated for a reference temperature, $T_{R}$, equal to $300 \mathrm{~K}$;

2) the dimensionless adiabatic temperature rise is expressed with respect to the initial nitric acid amount loaded in the reactor. 


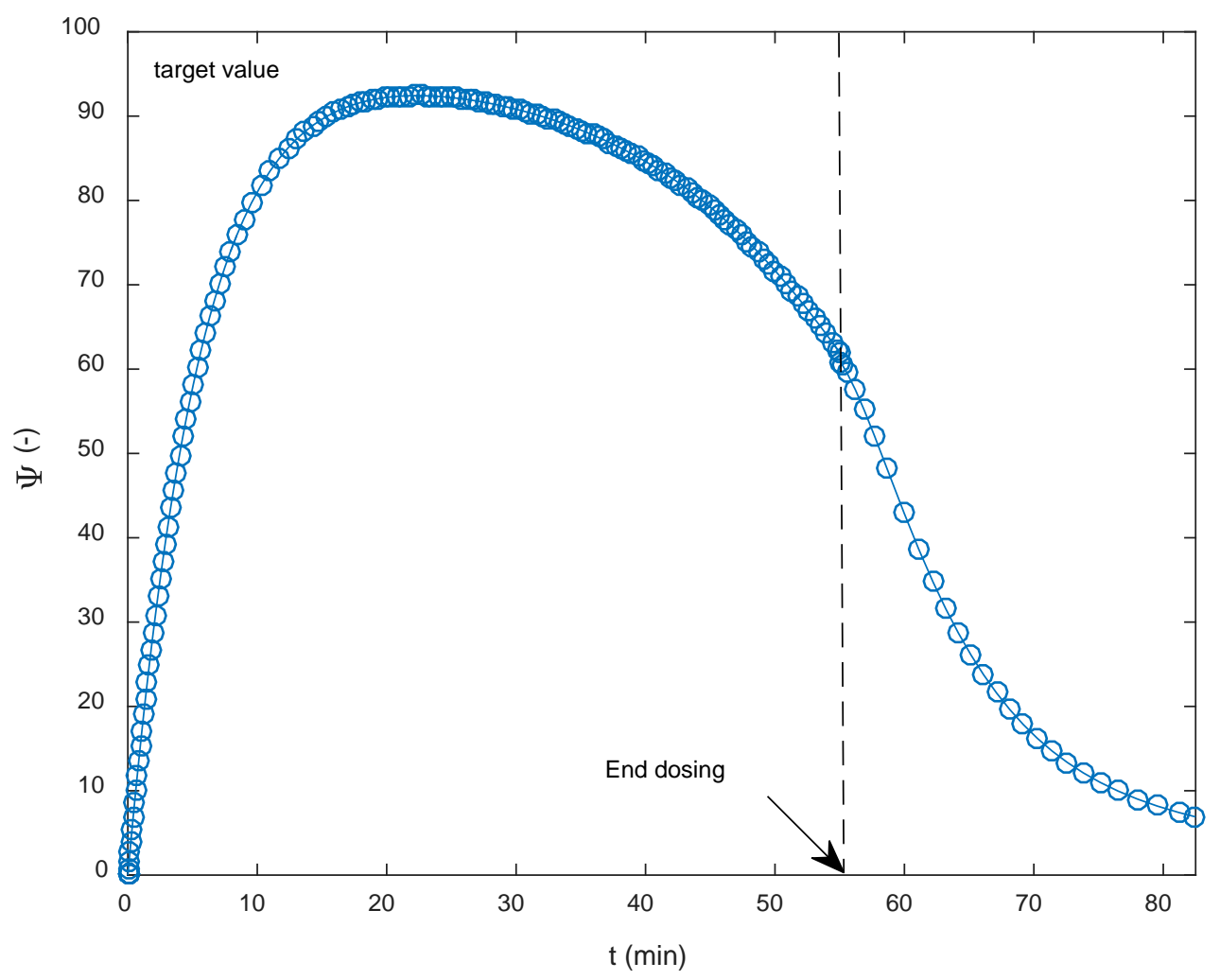

Fig. 1 


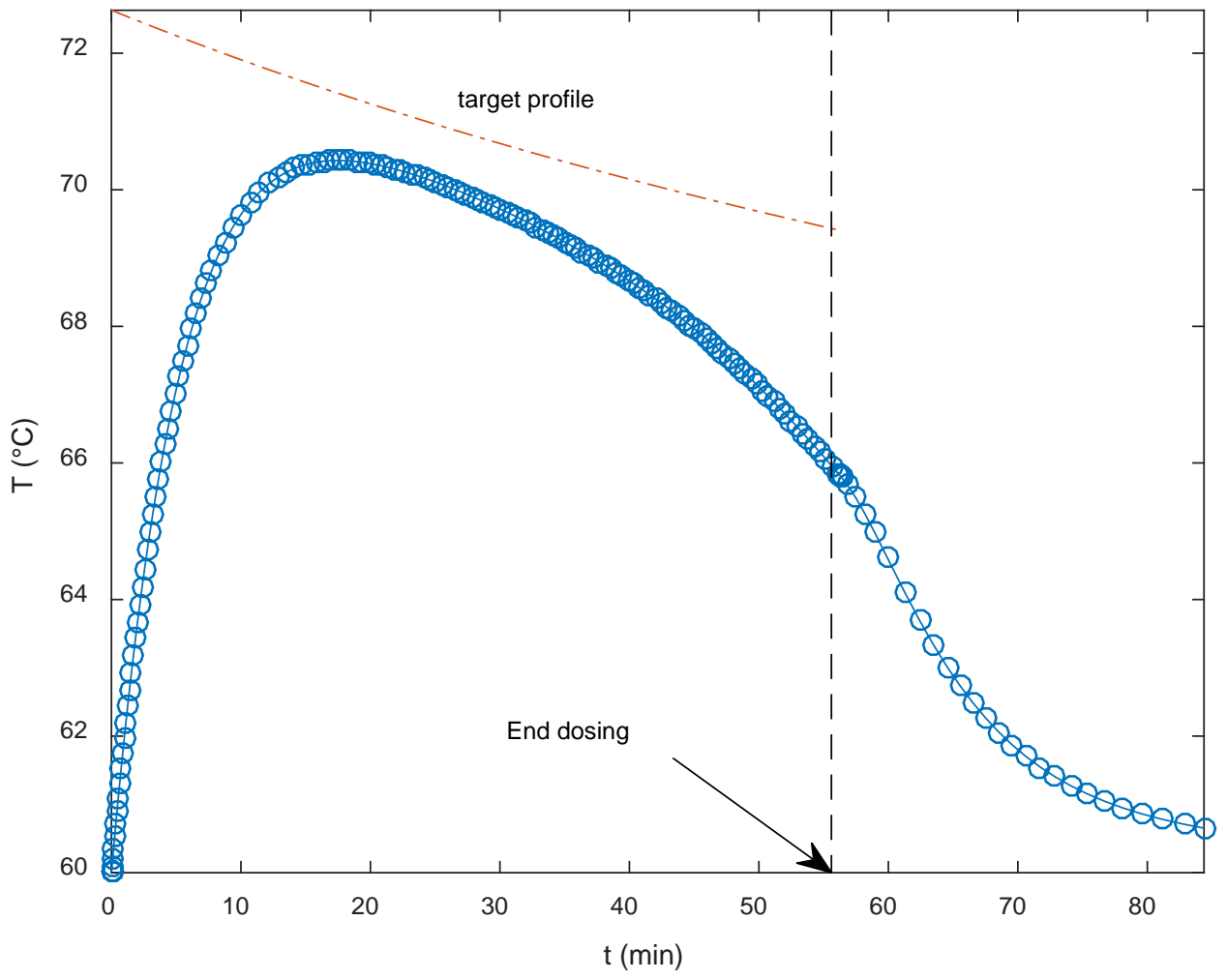

Fig. 2 


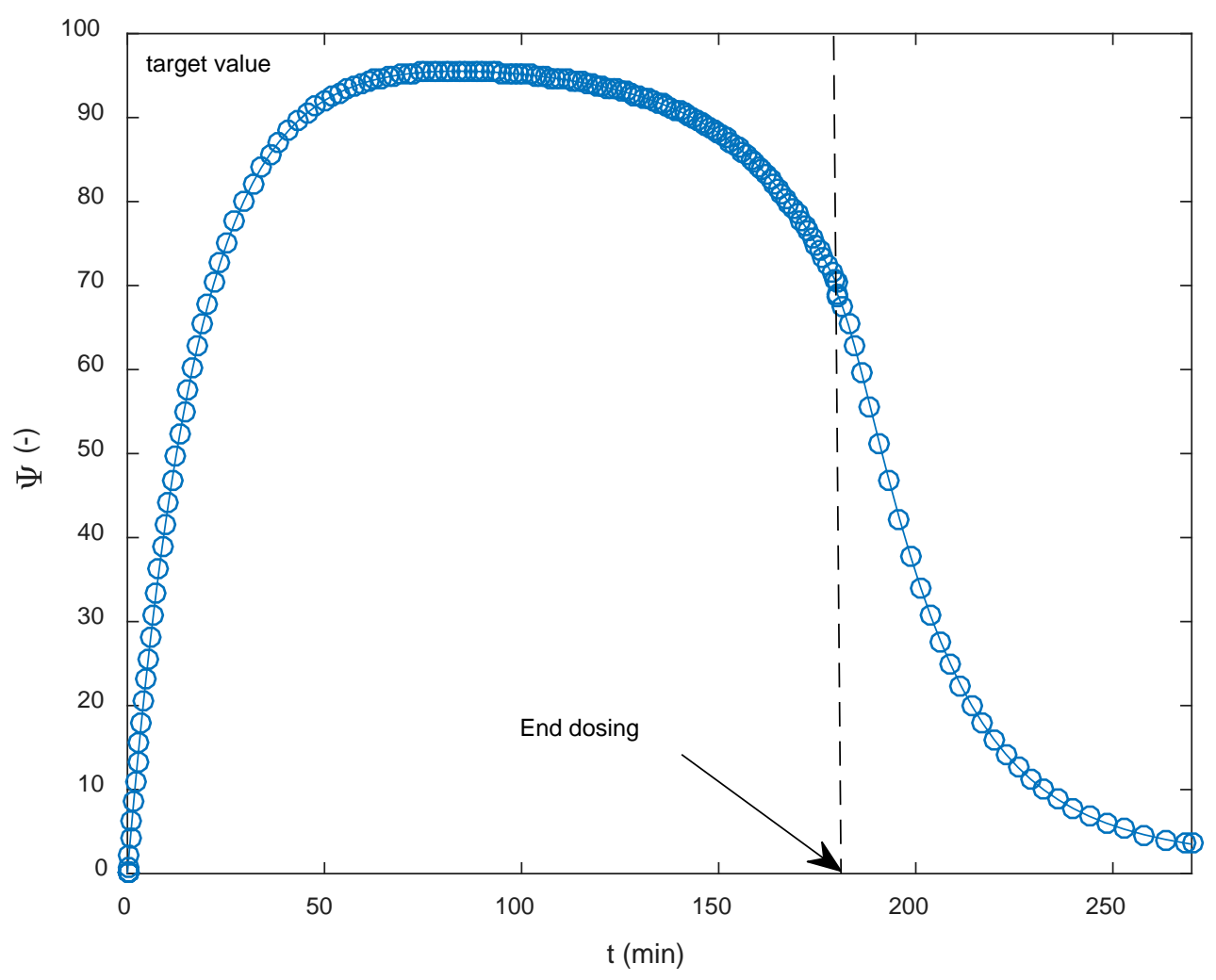

Fig. 3 


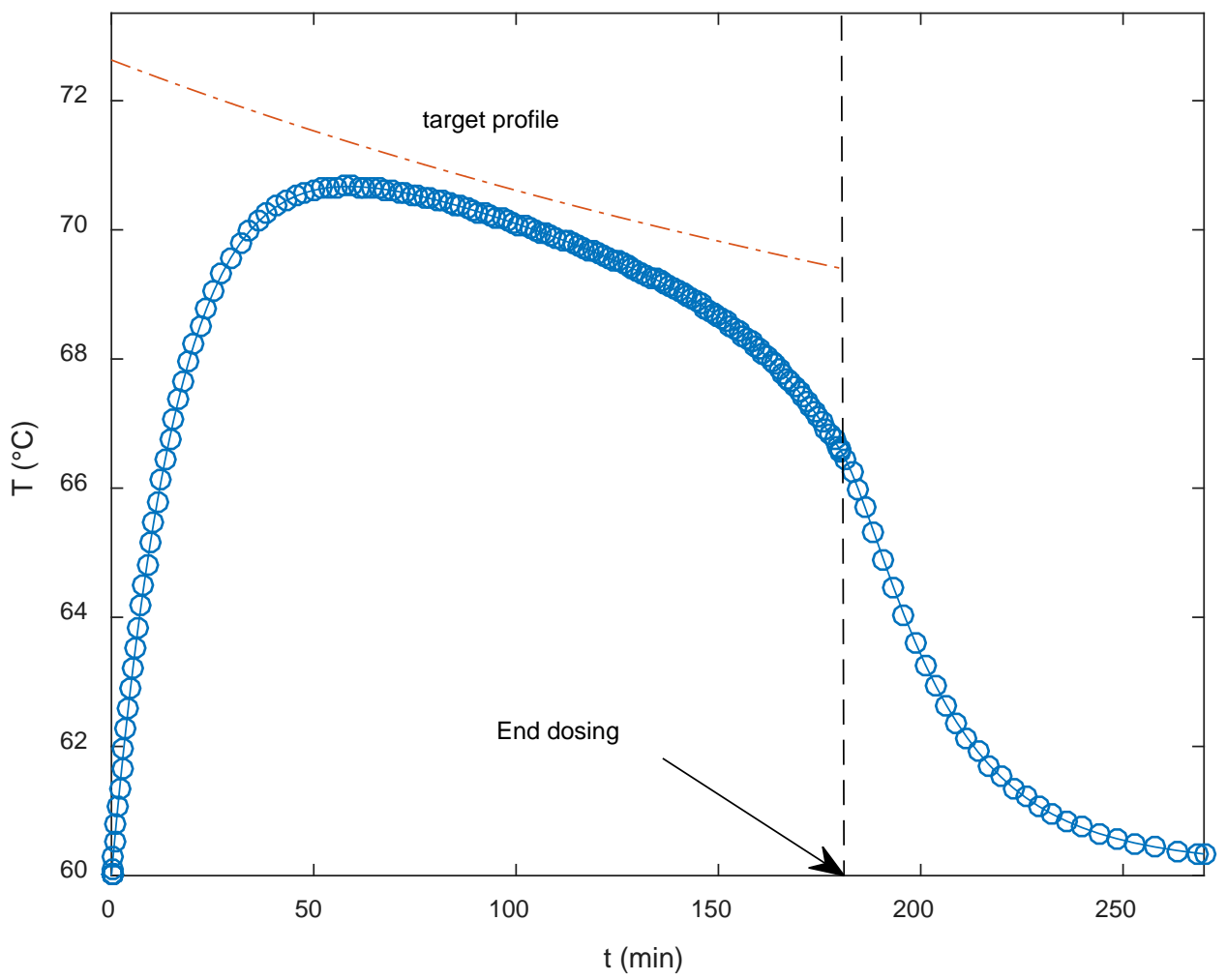

Fig. 4 


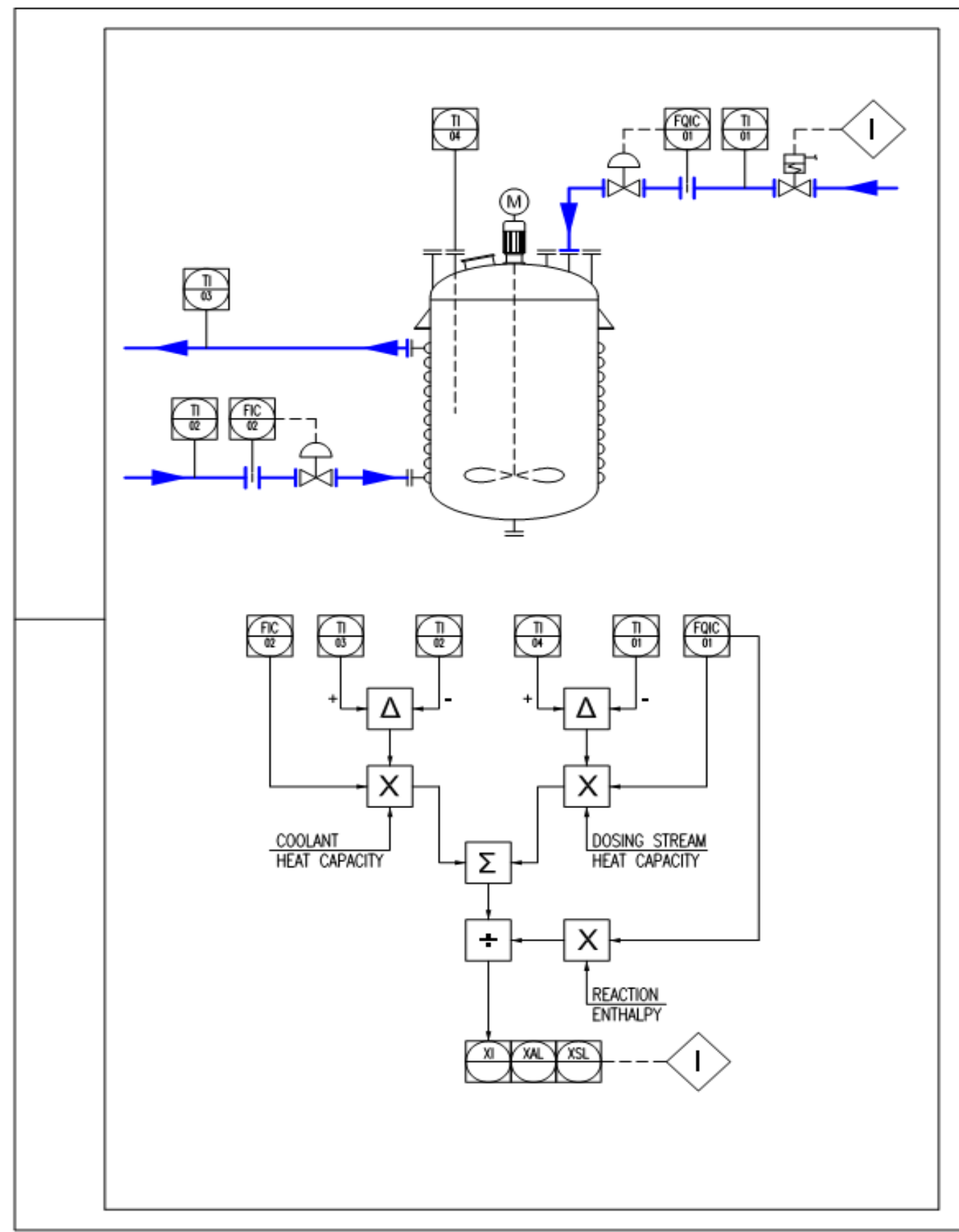

Fig. 5

30

DOI: 10.1021/acs.iecr.6b03590 


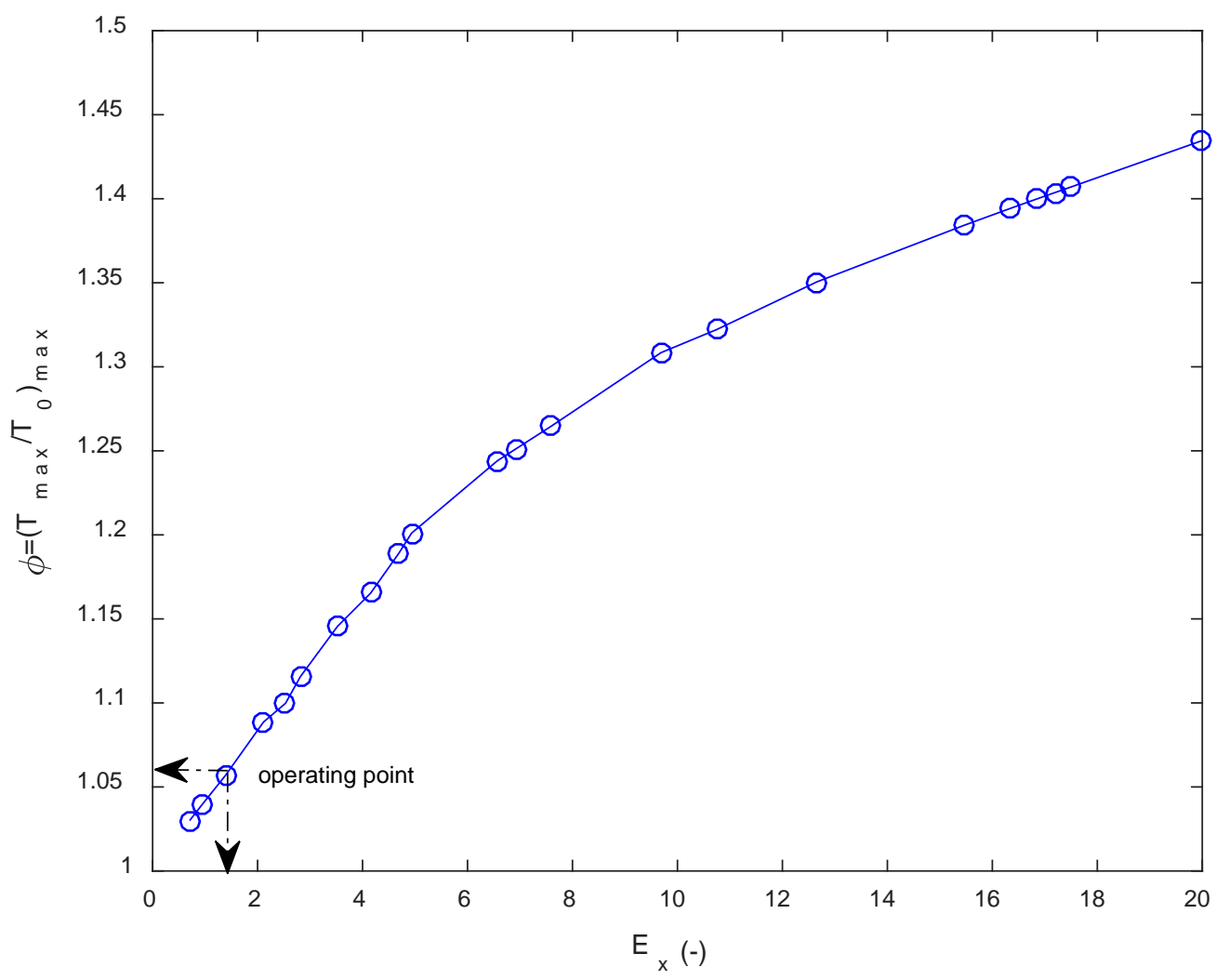

Fig. 6 


\section{For Table of Contents Only}

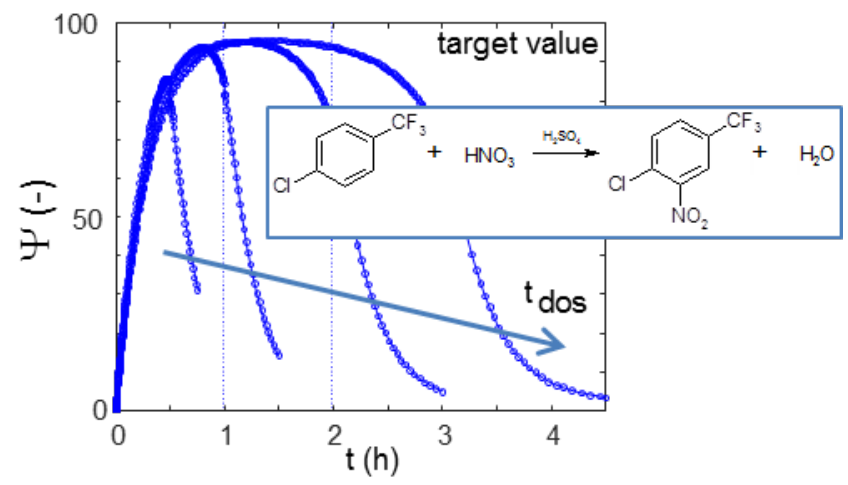

